\title{
Large-scale purification of pachydictyol A from the brown alga Dictyota dichotoma obtained from algal wash and evaluation of its antifouling activity against the freshwater mollusk Limnoperna fortunei
}

\author{
Gastón E. Siless $^{1,2}$ • Mónica García ${ }^{3}$ - Miriam Pérez ${ }^{3,4}$ • Guillermo Blustein ${ }^{3,5}$. \\ Jorge A. Palermo ${ }^{1,2}$
}

Received: 29 May 2017 / Revised and accepted: 29 August 2017

(C) Springer Science+Business Media B.V. 2017

\begin{abstract}
A scalable procedure was developed for the extraction and purification of pachydictyol $\mathrm{A}$, the main diterpenoid isolated from the brown alga Dictyota dichotoma. The organic extract of this species is a complex mixture of a large variety of diterpenes, and in this work, the protocol was employed successfully for the purification of gram quantities of this compound from Patagonian $D$. dichotoma collected from algal wash. Pachydictyol A, together with other minor diterpenoids, was tested for antifouling activity against the invading freshwater mussel Limnoperna fortunei, using a byssal thread formation assay. The results obtained in the study showed a potent antifouling activity for pachydictyol A at $4.7 \mu \mathrm{g} \mathrm{cm}^{-2}$ disk load. As for the other diterpenoids, dictyoxide was also considerably active, while dictyol $\mathrm{C}$ and dictyotadiol had a considerably lower activity. Taking into account the large biomass of algal wash and
\end{abstract}

Electronic supplementary material The online version of this article (https://doi.org/10.1007/s10811-017-1261-9) contains supplementary material, which is available to authorized users.

Jorge A. Palermo

palermo@qo.fcen.uba.ar

1 Departamento de Química Orgánica, Facultad de Ciencias Exactas y Naturales, Universidad de Buenos Aires, Ciudad Universitaria, Pabellón 2 - (1428), Buenos Aires, Argentina

2 Unidad de Microanálisis y Métodos Físicos en Química Orgánica (UMYMFOR), CONICET-Universidad de Buenos Aires, Buenos Aires, Argentina

3 Centro de Investigación y Desarrollo en Tecnología de PinturasCIDEPINT, Calle52 e/ 121 y 122, B1900AYB La Plata, Argentina

4 Facultad de Ciencias Naturales y Museo, Universidad Nacional de La Plata, Calle 60 y 122, 1900 La Plata, Argentina

5 Facultad de Ciencias Agrarias y Forestales, Universidad Nacional de La Plata, Calle 60 y 119, 1900 La Plata, Argentina the abundance of $D$. dichotoma, together with the effectiveness of the purification protocol, these results show that pachydictyol A and dictyoxide have a good chance to become natural, nontoxic, and ecologically friendly additives in antifouling paints for the protection of submersed structures against $L$. fortunei.

Keywords Pachydictyol A · Dictyota dichotoma . Phaeophyceae $\cdot$ Limnoperna fortunei $\cdot$ Antifouling activity . Algal wash

\section{Introduction}

Algal wash, the large volume of algae accumulated by the sea on the shores on a daily basis, is very abundant in the Patagonian region, especially in the spring and summer months. This phenomenon arises from a combination of weather conditions, currents, and tides that can produce massive dislodgements of algae from the subtidal benthic communities. These algal washes are especially important in regions of large tidal amplitudes and extensive subtidal algal coverage. However, this bioresource, which adds up to several thousand tons per year in some locations, is left to rot, or collected on a daily basis from the beach, which is an expensive procedure, only to be discarded in dumpsites or used for the preparation of compost. For example, on the shores of Puerto Madryn in northeastern Patagonia, Argentina, about 8000 tonnes of seaweed are collected every summer to avoid in situ rotting and at the same time reduce pollution that would interfere with recreational use of the beach. The discovery of new potential uses, which would add value to this biomass, is an exciting perspective, taking into account its availability and sustainability. Dictyota dichotoma is a very abundant species in the South Atlantic, especially along the Patagonian shores, and is one of the main biomass 
components of algal wash in the region. In the gulf of San Jose (Argentina), around $30 \%$ of the ocean floor at depths $<10 \mathrm{~m}$ is covered by $D$. dichotoma (Helbling et al. 2010). This species is also very abundant along the shores of the province of Buenos Aires and, in several locations, is the main component of wet biomass (Becherucci and Benavides 2016). Dictyota species are known among marine natural products researchers for the production of a great diversity of diterpenoids as secondary metabolites. However, the purification of some of these metabolites in large amounts is complicated by the chemical complexity of the extracts. Previous investigations on the organic extracts of Patagonian D. dichotoma indicated that pachydictyol A was by far the most abundant secondary metabolite, accompanied by related diterpenoids such as dictyoxide, dictyotadiol, and dictyol $\mathrm{C}$, together with several minor components (Palermo et al. 1994). In this work, a protocol was developed for a large-scale purification of pachydictyol A. This compound, isolated in gram-scale, was made available for chemical diversification projects and to explore possible biotechnological uses. In particular, in the present work, the use of some natural products extracted from $D$. dichotoma, pachydictyol A (1), dictyoxide (2), dictyotadiol (3), and dictyol $\mathrm{C}$ (4) (Fig. 1), as antifouling agents against the invading freshwater mussel Limnoperna fortunei, is explored.

\section{Materials and methods}

\section{General spectroscopic and chromatographic techniques}

NMR experiments were performed on a Bruker Avance 2 $(500 \mathrm{MHz})$ instrument at $500.13 \mathrm{MHz}$ for ${ }^{1} \mathrm{H}$ and 125.13 MHz for ${ }^{13} \mathrm{C}$. All spectra were recorded in $\mathrm{CDCl}_{3}$ using the central lines of the residual non-deuterated solvent as an internal standard. HR-ESIMS mass spectra were determined on a Bruker MicroQTOF instrument. Optical rotations were measured on a Perkin-Elmer 343 polarimeter. UV spectra were obtained on a Hewlett Packard 8453 spectrophotometer and IR spectra were recorded on a Nicolet Magna 550 spectrophotometer. Vacuum flash chromatography was carried out on TLC grade silicagel G (Merck). All solvents were distilled prior to use. HPLC purifications were performed using a Thermo Separations SpectraSeries P100 pump, a Thermo Separations Refractomonitor IV RI detector, and a Thermo Separations SpectraSeries UV 100 UV detector, HPLC grade solvents, and YMC RP-18 (5 $\mu \mathrm{m}, 20 \mathrm{~mm} \times 250 \mathrm{~mm} ; 5 \mu \mathrm{m}, 10 \mathrm{~mm} \times 250 \mathrm{~mm})$ columns. UV detection was performed at $220 \mathrm{~nm}$. TLCs were carried out on Merck Sílicagel $60 \mathrm{~F}_{254}$ plates, using $\mathrm{CH}_{2} \mathrm{Cl}_{2} /$ EtOAc mixtures as mobile phase. TLC plates were sprayed with $2 \%$ vanillin in concentrated $\mathrm{H}_{2} \mathrm{SO}_{4}$.

\section{Collection of $\boldsymbol{D}$. dichotoma, extraction and isolation}

Dictyota dichotoma was collected from algal wash at Las Grutas, province of Rio Negro, Argentina, and kept frozen until extraction. The frozen algae were extracted with ethanol $(\mathrm{EtOH})$ in a blender ( $1 \mathrm{~L} \mathrm{EtOH} \mathrm{kg}^{-1}$ of frozen algae). The extract was filtered and the residue was extracted again with ethyl acetate (EtOAc). The combined extracts were taken to dryness to give a green syrup, which was partitioned between cyclohexane/methanol (MeOH)-water (9:1) to yield lipophilic (EL) and polar (EP) subextracts. EL was subjected to vacuum flash chromatography on silicagel using a cyclohexane/ dichloromethane $\left(\mathrm{CH}_{2} \mathrm{Cl}_{2}\right)$ /EtOAc gradient. The first fraction, which was eluted with cyclohexane, contained hydrocarbons, carotenoids, and fats. The second fraction, which was eluted
Fig. 1 D. dichotoma diterpenes tested for antifouling activity

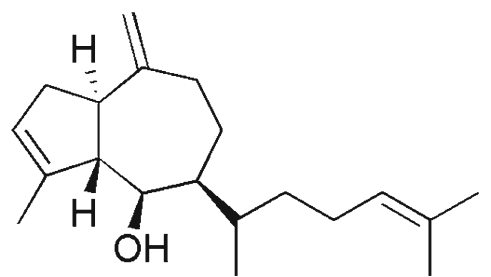

1: pachydictyol A

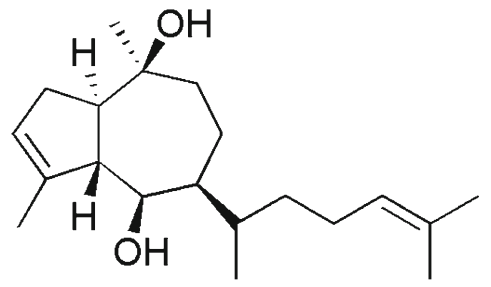

3: dictyol C

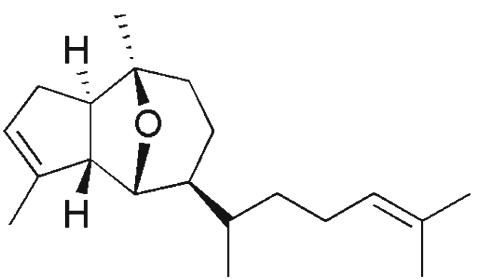

2: dictyoxide

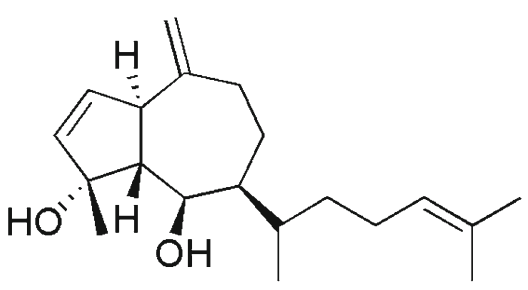

4: dictyotadiol 
with cyclohexane/ $\mathrm{CH}_{2} \mathrm{Cl}_{2}$ (9:1), had the largest content of pachydictyol A when examined by TLC and was named pachydictyol-enriched fraction (PEF). A typical yield is as follows: from $8 \mathrm{~kg}$ of alga, $270 \mathrm{~g}$ of crude extract were obtained, which yielded $26 \mathrm{~g}$ of EL, and finally $5.5 \mathrm{~g}$ of PEF. In order to get pure standards of the diterpenoids, PEF was initially purified by reversed-phase HPLC using $\mathrm{MeOH} / \mathrm{H}_{2} \mathrm{O}$ (9:1) as mobile phase, to yield pure samples of pachydictyol A (1) and dictyoxide (2). On the other hand, fraction 4 (eluted from vacuum flash chromatography with cyclohexane/ $\mathrm{CH}_{2} \mathrm{Cl}_{2}(7: 3)$ ) yielded by HPLC purification dictyotadiol (3) and dictyol C (4).

\section{Large-scale purification of pachydictyol A}

PEF (1 g) was dissolved in pyridine $(4 \mathrm{~mL})$, and then trifluoroacetic anhydride was added in small portions while stirring at $0{ }^{\circ} \mathrm{C}$ with TLC monitoring, until complete esterification of pachydictyol A. Then, EtOH was added to destroy the excess of trifluoroacetic anhydride. The reaction mixture was diluted with EtOAc $(200 \mathrm{~mL})$ and then washed twice with $1 \mathrm{M} \mathrm{HCl}(100 \mathrm{~mL})$ and twice with brine $(100 \mathrm{~mL})$. The organic layer was taken to dryness, and the crude product was subjected to column chromatography on silicagel using cyclohexane: $\mathrm{CH}_{2} \mathrm{Cl}_{2}$ (97:3) as mobile phase, to obtain $570 \mathrm{mg}$ of pure TFA-pachydictyol A. A typical procedure for the deprotection of TFA-pachydictyol $\mathrm{A}$ is as follows: TFApachydictyol A (52.7 mg, $0.137 \mathrm{mmol})$ is dissolved in $2 \mathrm{~mL}$ of a saturated solution of $\mathrm{K}_{2} \mathrm{CO}_{3}$ in $\mathrm{MeOH}$ and stirred at room temperature for $30 \mathrm{~min}$, with TLC monitoring. When the reaction was complete, the mixture was diluted with $50 \mathrm{~mL}$ of EtOAc and washed with water until neutrality. The solvent was evaporated and the crude product was dissolved in cyclohexane and percolated through a small column of silica gel, eluting with cyclohexane: $\mathrm{CH}_{2} \mathrm{Cl}_{2}(8: 2)$ to yield $39.0 \mathrm{mg}$ of pure pachydictyol A ( $98.7 \%$ yield).

Pachydictyol A (1) NMR spectra: see the Supplementary Material.

Dictyoxide (2) NMR spectra: see the Supplementary Material.

Dictyotadiol (3) NMR spectra: see the Supplementary Material.

Dictyol C (4) NMR spectra: see the Supplementary Material.

TFA-pachydictyol A NMR spectra: see the Supplementary Material.

\section{Biological activity}

\section{Mussel specimens}

Juvenile specimens of Limnoperna fortunei were collected during low tide at Punta Lara (Ensenada, Buenos Aires,
Argentina). The samples were transferred to an aquarium with river water and aged tap water at room temperature $\left(23{ }^{\circ} \mathrm{C}\right)$ and natural sunlight. The mussels were fed daily, and every 2 days, half of the water in the aquarium was renewed. The mussels chosen for the experiments were selected based on their size (valve length, $0.8-1.3 \mathrm{~mm}$ ) and their active exploratory behavior.

\section{Byssal thread formation assay}

The laboratory screening method used for the evaluation of byssal thread formation of $L$. fortunei is a modification of the technique described by Ina et al. (1989). Paper disks of $9 \mathrm{~cm}$ diameter were soaked in methanol, and, after air drying, were attached to the base of $10 \mathrm{~cm}$ diameter Petri dishes. Methanolic solutions of the study compounds were prepared, of the following concentrations: 25, 33.5, 67, and $85 \mu \mathrm{g} \mathrm{mL}^{-1}$. Paper sample disks of $3 \mathrm{~cm}$ diameter were soaked with $1 \mathrm{~mL}$ of the study solution. In this way, each disk was loaded with $3.5,4.75,9.5$, or $12 \mu \mathrm{g} \mathrm{cm}^{-2}$ of study compound. The disks were allowed to air-dry, and then the sample disks were placed on the center of the base paper disks, on the previously prepared Petri dishes. Four mussels were placed on each sample disk, attached by the left valve, with the umbo facing the center of the disk and then were covered with $50 \mathrm{~mL}$ of aged tap water. Control dishes were also prepared with sample disks soaked only in methanol. The Petri dishes were incubated in the dark at $25^{\circ} \mathrm{C}$ for $24 \mathrm{~h}$. Then, the number of byssal threads attached outside the sample disk (A) was counted, as well as the total number of secreted byssal threads (B). The antifouling activity was calculated as the percentual ratio $\mathrm{A} / \mathrm{B} \times 100$. If the ratio was $100 \%$ it was assigned $\mathrm{a}+2$ score, a ratio between 80 and $100 \%$ was assigned a +1 score, while a ratio between 50 and $80 \%$ was considered +- . A ratio lower than $50 \%$ was considered inactive. The test was performed in triplicate. A typical experiment is shown in Fig. 2.

\section{Results and discussion}

Pachydictyol A (1) is one of the first isolated, and the best known, of the more than 200 Dictyota diterpenoids and can be found in several species, although at different concentrations (Blunt et al. 2016). Pachydictyol A has a very interesting bioactivity profile. Although the established ecological role of this diterpene is as a chemical defense to prevent grazing by marine herbivores, there are also reports of other biological activities (Hay et al. 1987a,b). For example, pachydictyol A has shown selective antiviral activity: the compound was inactive against poliomyelitis virus I and herpes simplex virus I, but was nonetheless active against the HSV-1 virus (Pereira et al. 2004, Siamopoulou et al. 2004). Pachydictyol A also displayed anticoagulant activity (Moura et al. 2014). In a 
Fig. 2 Byssal thread formation assay (from left to right): control, $t=0 \mathrm{~h}$; control, $t=24 \mathrm{~h}$; pachydictyol A, $t=24 \mathrm{~h}$
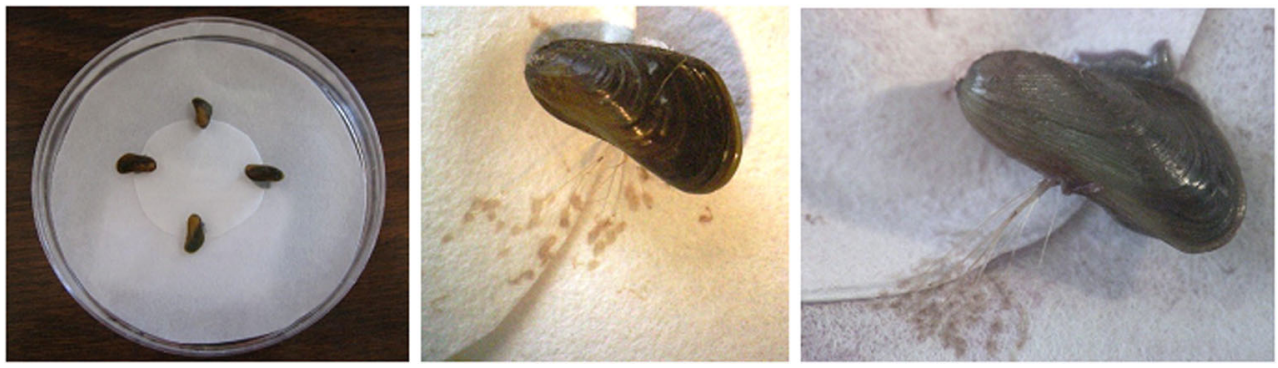

previous report, some antifouling activity was informed for pachydictyol A against Bugula neritina larvae, but the authors declared that the results were not conclusive (Schmitt et al. 1998). Interestingly, pachydictyol A has very low cytotoxicity and has shown no toxic effects to mice in in vivo studies. These bioactivity data, together with the abundance of the natural sources, make pachydictyol A an interesting compound for possible biotechnological uses, as well as a starting compound for chemical diversification projects.

However, a simple and efficient protocol for the isolation of pachydictyol A at gram scale was mandatory for the viability of these projects. In the present work, a scalable procedure was developed for the purification of pachydictyol A in gram quantities. To make this process environmentally friendly, $D$. dichotoma was collected from algal wash, in this case at Las Grutas, Rio Negro, Argentina. The algal material was extracted in a blender with $\mathrm{EtOH}$, and the crude extract was partitioned (see the "Materials and methods" section) to yield lipophylic and polar extracts. Pachydictyol A is the main diterpenoid present in the lipophylic extract; however, the chromatographic profile of this extract is complex due to the presence of a wide array of minor diterpenoids and lipids, making the large-scale purification of pachydictyol A a complicated task. Fractionation of this extract by vacuum flash chromatography is a quick and scalable one-step procedure, which furnishes a pachydictyol-enriched fraction (PEF) free from the less polar and more polar components of the extract. However, the final purification of pachydictyol A from this fraction is not simple. PEF has three main components: pachydictyol A, the related diterpene dictyoxide, and fatty acid esters (usually ethyl esters formed during extraction). Pachydictyol A is an oil; so direct crystallization is not possible. The small Rf differences of these components on silica gel TLC makes typical column chromatography an inefficient procedure. This leaves reversed-phase HPLC as the only efficient technique for the direct purification of pachydictyol A from PEF. However, this is a slow and expensive procedure when scaled-up to gram quantities. For this reason, an alternative approach was developed, making use of the structural differences of the components of PEF to achieve a selective derivatization which enabled a simplified chromatographic separation. Of the three main components of PEF, pachydictyol A is the only one that has a free hydroxyl group.
Derivatization of this secondary hydroxyl to form an ester would lower the polarity of the compound and allow an easy chromatographic separation of pachydictyol A from the other components of PEF. The most obvious choice for this purpose was acetylation; however, the results were disappointing. Seventeen different acetylation procedures were tried on an HPLC-purified pachydictyol A sample, with a list of reagents and conditions that included the use of microwave heating, $\mathrm{Ac}_{2} \mathrm{O}$ and $\mathrm{AcCl}$ with a variety of catalysts such as py, DMAP, $\mathrm{Sc}(\mathrm{OTf})_{3}$, and $\mathrm{La}\left(\mathrm{NO}_{3}\right)_{3}$, among others. In all cases, the final yields of acetylated product were lower than $30 \%$, which was in accordance with the observation in the original report on the isolation and identification of pachydictyol A, that this compound forms an acetate with great difficulty (Hirschfeld et al. 1973).

For this reason, the trifluoroacetyl group was then chosen for the derivatization of PEF. Trifluoroacetylation is a more favorable acylation reaction than simple acetylation. Besides, the trifluoroacetyl group is easier to hydrolyze than the acetyl group. To our delight, esterification of pachydictyol A with trifluoroacetic anhydride was quantitative, and the trifluoroacetyl group could be easily removed later by mild basic hydrolysis. TFA-pachydictyol A has a much lower polarity than the other components of PEF, and a simple column chromatography on silica gel allowed the purification of this compound, helped by the previous removal by dry vacuum flash chromatography in the previous step, of the less polar components of the extract. Another advantage of this purification scheme is that TFA-pachydictyol A purified in this way can be used directly as starting material for chemical diversification projects since the hydroxyl group at C-6 is already protected. A mild basic hydrolysis with $\mathrm{K}_{2} \mathrm{CO}_{3}$ in $\mathrm{MeOH}$ afforded pachydictyol A in quantitative yield. The complete purification procedure is outlined in Scheme 1. By the use of this procedure, it was possible to isolate $1.5-3 \mathrm{~g}$ of pure pachydictyol A from $10 \mathrm{~kg}$ of fresh $D$. dichotoma collected from the algal wash. This amount of alga can be easily collected by one person in a morning's work at the beach during high tide, or at tidal pools during low tide. When the procedure was applied to air-dried algae, the final yields were considerably lower.

With a reliable supply of pachydictyol A, the possibility of technological applications for this compound become 


\section{Dictyota dichotoma from algal wash}

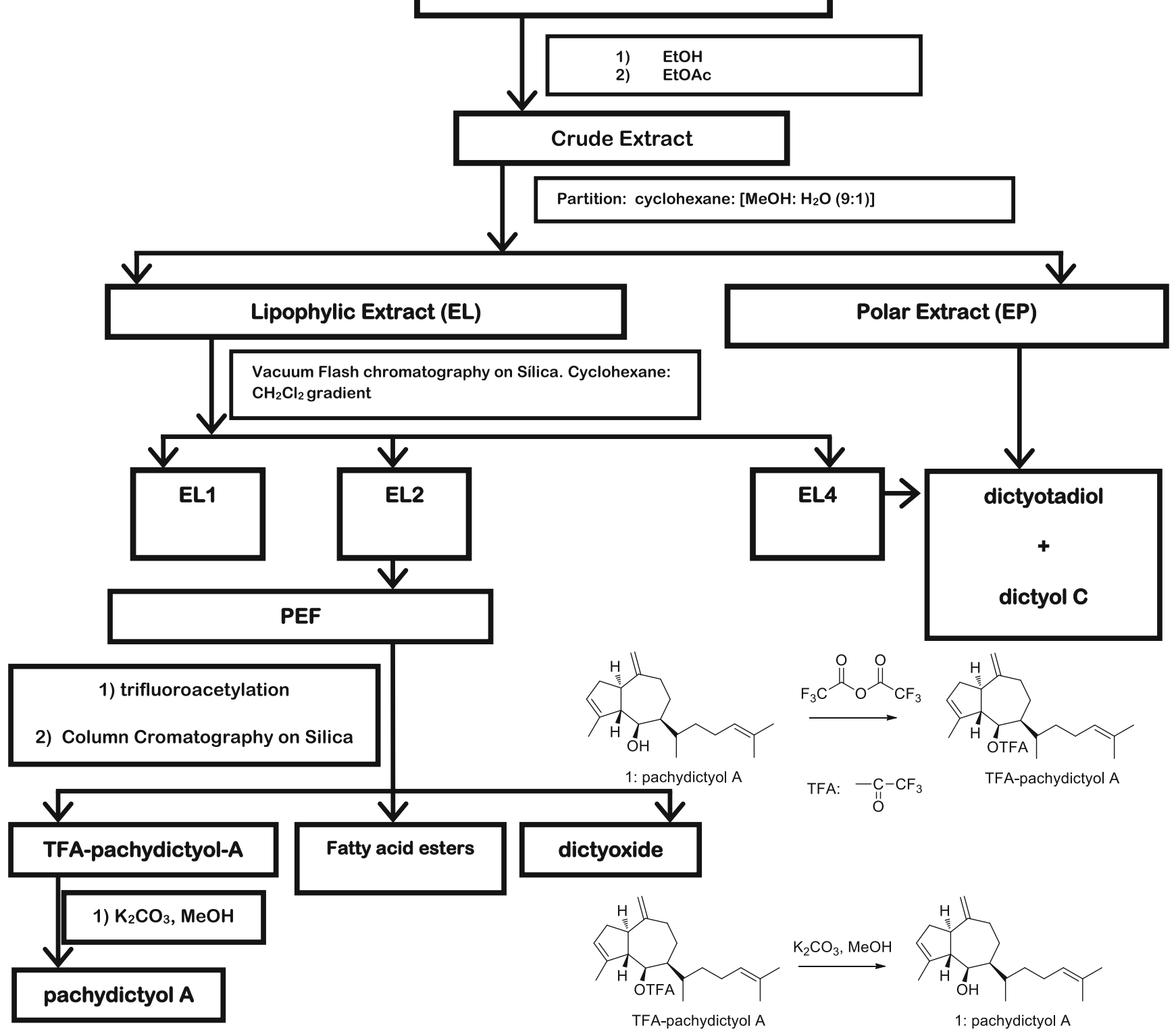

Scheme 1 Large-scale purification of pachydictyol A

available, such as its possible use as an antifouling agent. The marine environment offers a wealth of information about antifouling natural products. The usually limited supply of these natural antifoulants poses a sustainability problem that hampers their development in an industrial scale, which, in this case of pachydictyol A was overcome by the purification protocol developed in the present work, enabling future studies towards the development of an efficient antifouling coating, as a greener approach compared to the use of more aggressive biocides.

The interest in the control of biofouling is not limited to marine species, since some invasive freshwater mussels represent a serious concern with economic and ecological consequences. Previous investigations have shown that some diterpenoids isolated from Dictyota spp., displayed antifouling activity on marine organisms, in particular against the marine mussel Perna perna (Barbosa et al. 2007, Viano et al. 2009). Based on these results, it was then possible that similar compounds could also have antifouling activity against the invading freshwater species $L$. fortunei, a hypothesis that was tested in the present work, with the aim at a possible use as additives in antifouling coatings.

The Asian freshwater mollusk, L. fortunei (golden mussel), is a bivalve that was introduced in South America to Rio de la Plata by careless shipping practices, probably with ballast water of a ship trading with East Asia (Boltovskoy, 2015). Since 
the initial reports of its occurrence in Argentina in 1991 (Pastorino et al. 1993), it has spread rapidly, colonizing the whole Rio de la Plata basin (Darrigran and Pastorino 2004), which encompasses Paraná, Paraguay and Uruguay rivers, as well as the Pantanal region (Central West Brazil) and the endorheic Mar Chiquita lagoon in central Argentina (Boltovskoy et al. 2006). The spread of this invading species has been quite fast, covering more than $2000 \mathrm{~km}$ in 20 years (Oliveira et al. 2010). The golden mussel attaches to almost any hard surface using its glue-like byssal threads and can form thick mats of several hundred thousand individuals per square meter. These mussels spend their adult lives attached to hard substrata such as rocks and cobbles, as well as to concrete, iron, polyvinyl chloride, plastic, and fiberglass. In industrial facilities, fouling by this species can cause pipe clogging, pollution by dead mussels, increased resistance to water flow, jamming of components, and enhanced corrosion, among other nuisances. Piping systems at public and private facilities as well as turbines in hydroelectric power plants that use raw water are particularly prone to golden mussel infestations, which produce severe economic losses. Other kinds of activities are also affected, such as fish farming facilities and tourism. Besides the economic problems, there are also ecological impacts, including the relationship of the invading mussels with the local biota, which have not been fully assessed (Boltovskoy and Correa 2015).

Since the invasion of $L$. fortune $i$ is now firmly established, control and mitigation strategies become crucial, especially for the protection of submersed structures. The current available procedures include manual or mechanical cleaning, chemical treatment of the water, thermal treatment, oxygen deprivation, dessication, and the use of protective coatings (Matsui et al. 2002, Perepelizin and Boltovskoy 2011). Most of these methods have severe drawbacks: many of them are time consuming, need operational shutdown, demand a large workforce, or pose injury risks to personnel. Others are only applicable in closed environments. In particular, the use of chemicals to control mussel infestations can be extremely harmful to the environment, and a variety of chemicals are currently used, which include oxidizing (chlorine) as well as non-oxidizing agents, basic compounds to control $\mathrm{pH}$ $(\mathrm{NaOH})$, and detergents. Chlorine, which is one of the more popular chemicals, can also pose health hazards to the workers (Claudi and Oliveira, 2015).

On the other hand, the use of antifouling coatings has the advantage that they can be used in combination with other of the abovementioned methods and can be applied in industrial facilities as well as for the protection of submersed objects in open environment water bodies such as rivers or reservoirs. Several tests were performed with experimental paints to produce low energy surfaces, which can affect the adhesion of byssal threads with or without the addition of biocides (Ohkawa et al. 1999). Some of the typical paint biocides, such as copper ions, are toxic and harmful to other species as well, so there is a need to develop less toxic and environmentally friendly additives to produce antifouling coatings. In this context, antifouling natural products are a valuable and biodegradable alternative for the replacement of toxic biocides.

Compounds 1-4 were studied for antifouling activity against $L$. fortunei using a byssal thread formation assay, and the results are shown in Table 1. Among the tested compounds, only pachydictyol A (1) and dictyoxide (2) showed significant inhibition of byssal thread formation at $4.7 \mu \mathrm{g} \mathrm{cm}^{-2}$, while compound $\mathbf{1}$ still showed some activity at $3.5 \mu \mathrm{g} \mathrm{cm}^{-2}$. Regarding the other two natural diterpenoids, dictyol C (3) and dictyotadiol (4), they were only moderately active at 9.5 and $12 \mu \mathrm{g} \mathrm{cm}^{-2}$, respectively. No toxic effects were observed in the mussels by the use of the tested compounds. In order to be effective as antifouling agents on a submerged surface, an active compound should have a very limited water solubility to avoid diffusion along the water column. This is indeed the case for compounds $\mathbf{1}$ and $\mathbf{2}$, which were the most active substances. Compounds $\mathbf{3}$ and $\mathbf{4}$, which are more polar, and their water solubility is comparably higher, are less active.

There has been some discussion about the validity of the mussel test for antifouling activity, when compared to field tests, in terms of the range of species included in the study, and the concentrations of the tested compounds, which should ideally match the natural concentrations in the parent organism, especially when the aim of the test is to obtain ecologically relevant data (Da Gama et al. 2003). However, in the present experiment, the goal was to test the byssal thread formation of the target species, regarding the possible use of these compounds in an antifouling coating. For these reasons, there was no need to take into account the original concentrations present in the algae, especially considering that the compounds were isolated from a marine algae, and that the possible use was against a freshwater mussel. Another aspect to take into consideration is that there was no need to expose the compounds to a more diverse array of species, since there are no other fouling mussels in the Rio de la Plata basin.

Table 1 Antifouling activity scores of compounds 1-4 against L. fortunei

\begin{tabular}{lllll}
\hline Compound & \multicolumn{4}{l}{ Tested concentration $\left(\mu \mathrm{g} \mathrm{cm}^{-2}\right)$ activity score } \\
\cline { 2 - 5 } & 3.5 & 4.7 & 9.5 & 12 \\
\hline Pachydictyol A (1) & \pm & +1 & +2 & +2 \\
Dictyoxide (2) & - & +1 & +1 & +1 \\
Dictyol C (3) & - & - & +1 & +2 \\
Dictyotadiol (4) & - & - & \pm & +1 \\
Control & - & - & - & - \\
\hline
\end{tabular}


The results obtained in this work show that pachydictyol A and dictyoxide are good candidates for additional tests as additives in antifouling coatings, as a greener approach compared to the use of more aggressive biocides. Both compounds are non-toxic and do not have significant antibiotic activity, and their action is probably based on a modification of the surface properties that leads to a suppression of byssal thread release. The low water solubility of both compounds will ensure a slow leaching rate. Further field experiments with experimental paints will be needed to check these results and to transform these natural products into an efficient antifouling coating. It would be interesting to test also the pachydictyol A enriched fraction (PEF), since, of the remaining compounds from this fraction, dictyoxide is also bioactive, and the fatty acids ethyl esters would be very compatible with the paint vehicle. The use of PEF would eliminate the need of the purification step of pachydictyol A, enabling larger yields of bioactive material per kilogram of algal tissue. If the biological activity observed in the paper disk assay can be translated into an antifouling paint, then the required amounts of pachydictyol (or PEF) would be perfectly compatible with the quantities of algal wash and the yields of purified compound. The collection of plant material was ecologically friendly since $D$. dichotoma was collected from algal wash, which is a sustainable resource and produces no harm to the environment. In this way, pachydictyol A and dictyoxide have a good chance to become natural, non-toxic, and ecologically friendly additives in antifouling paints for the protection of submersed structures against $L$. fortunei.

Acknowledgements This work was supported by ANPCyT (Argentina) under Grant PICT-2010-1808, CONICET (Argentina) under Grant 11220090100516, and the University of Buenos Aires under Grant UBACyT 20020100100704. The CIDEPINT group thanks Consejo Nacional de Investigaciones Científicas y Técnicas (CONICET), Comisión de Investigaciones Científicas de la provincia de Buenos Aires (CIC), and Universidad Nacional de La Plata (Argentina) for their financial support.

\section{References}

Barbosa JP, Fleury BG, Da Gama BAP, Teixeira VL, Pereira RC (2007) Natural products as antifoulants in the Brazilian brown alga Dictyota pfaffii (Phaeophyta, Dictyotales). Biochem Syst Ecol 35:549-553

Becherucci M, Benavides H (2016) Composición florística de arribazones de algas marinas en playas del sudeste de la provincia de Buenos Aires, Argentina. Iheringia, Série Botânica 71:22-26

Blunt JW, Copp BR, Keyzers RA, Munro MHG, Prinsep MR (2016) Marine natural products. Nat Prod Rep 33:382-431 and previous reviews

Boltovskoy D, Correa N, Cataldo D, Sylvester F (2006) Dispersion and ecological impact of the invasive freshwater bivalve Limnoperna fortunei in the Rio de la Plata watershed and beyond. Biol Invasions 8:947-963
Boltovskoy D (ed) (2015) Limnoperna fortunei. The ecology, distribution and control of a swiftly spreading invading fouling mussel. Springer International, Cham

Boltovskoy D, Correa N (2015) Ecosystem impacts of the invasive $b i$ valve Limnoperna fortunei (golden mussel) in South America. Hydrobiologia 746:81-95

Claudi R, Oliveira M (2015) Chemical strategies for the control of the golden mussel (Limnoperna fortunei) in industrial facilities. In: Boltovskoy D (ed) Limnoperna fortunei. The ecology, distribution and control of a swiftly spreading invasive fouling mussel. Springer International, Cham, pp 417-441

Da Gama BAP, Pereira RC, Soares AR, Teixeira VL, YoneshigueValentin Y (2003) Is the mussel test a good indicator of antifouling activity? A comparison between laboratory and field assays. Biofouling 19:161-169

Darrigran GA, Pastorino G (2004) Distribution of the golden mussel Limnoperna fortunei (Dunker 1857), (Bivalvia: Mytilidae) after 10 years invading America. J Conchol 3:95-101

Hay M, Duffy E, Pfister C, Fenical W (1987a) Chemical defense against different marine herbivores. Are amphipods insect equivalents? Ecology 68:1567-1580

Hay M, Fenical W, Gustafson K (1987b) Chemical defense against diverse coral-reef herbivores. Ecology 68:1581-1591

Helbling W, Villafañe V, Häder D (2010) Ultraviolet radiation effects on macroalgae from Patagonia, Argentina. In: Israel A, Einav R, Seckbach J (eds) Seaweeds and their role in globally changing environments. Springer, Dordrecht, pp 199-124

Hirschfeld DR, Fenical W, Lin G, Wing RM, Radlick P, Sims JJ (1973) Marine natural products. VIII. Pachydictyol A, an exceptional diterpene alcohol from the brown alga, Pachydictyon coriaceum. J Am Chem Soc 95:4049-4050

Ina K, Takasawa R, Yagi A, Yamashita N, Etoh H (1989) An improved assay method for antifouling substances using the blue mussel Mytilus edulis. Agric Biol Chem 53:3319-3321

Matsui Y, Nagaya K, Funahashi G, Goto Y, Yuasa A, Yamamoto H, Ohkawa K, Magara Y (2002) Effectiveness of antifouling coatings and water flow in controlling attachment of the nuisance mussel Limnoperna fortunei. Biofouling 18:137-148

Moura LA, De Almeida AM, Domingos TFS, Ortiz-Ramirez F, Cavalcanti DN, Teixeira VL, Lopes Fuly A (2014) Antiplatelet and anticoagulant effects of diterpenes isolated from the marine alga Dictyota menstrualis. Mar Drugs 12:2471-2484

Ohkawa K, Nishida A, Honma R, Matsui Y, Nagaya K, Yuasa A, Yamamoto H (1999) Studies on fouling by the freshwater mussel Limnoperna fortunei and the antifouling effects of low energy surfaces. Biofouling 13:337-350

Oliveira MD, Hamilton SK, Jacobi CM (2010) Forecasting the expansion of the invasive golden mussel Limnoperna fortunei in Brazilian and North American rivers based on its occurrence in the Paraguay river and Pantanal wetlands of Brazil. Aquat Invasions 5:59-73

Palermo J, Bernardo JJ, Seldes A (1994) Dictyol-D monoacetate and other diterpenoids from the brown alga Dictyota dichotoma. Anales Asoc Quim Arg 82:355-356

Pastorino G, Darrigran GA, Martin SM, Lunaschi L (1993) Limnoperna fortunei (Dunker 1857) (Mytilidae), nuevo bivalvo invasor en aguas del Rio de la Plata. Neotropica 39:101-102

Pereira HS, Leao-Ferreira LR, Moussatché N, Teixeira VL, Cavalcanti DN, Costa LJ, Diaz R, Frugulhetti IC (2004) Antiviral activity of diterpenes isolated from the Brazilian marine alga Dictyota menstrualis against human immunodeficiency virus type 1 (HIV1). Antivir Res 64:69-76

Perepelizin P, Boltovskoy D (2011) Thermal tolerance of Limnoperna fortunei to gradual temperature increase and its applications for biofouling control in industrial and power plants. Biofouling 27:667674 
Schmitt TM, Lindquist N, Hay M (1998) Seaweed secondary metabolites as antifoulants: effects of Dictyota spp. diterpenes on survivorship, settlement, and development of marine invertebrate larvae. Chemoecology 8:125-131

Siamopoulou P, Bimplakis A, Iliopoulou D, Vagias C, Cos P, Vanden Berghe D, Roussis V (2004) Diterpenes from the brown algae
Dictyota dichotoma and Dictyota linearis. Phytochemistry 65: 2025-2030

Viano Y, Bonhomme D, Camps- Jardin M, Culioli G (2009) Diterpenoids from the mediterranean brown alga Dictyota sp evaluated as antifouling substances against a marine bacterial biofilm. J Nat Prod 72: 1299-1304 